\title{
Co-Transplantation of Hypoxia Pretreated Human Adipose Derived Mesenchymal Stem Cells and Cord Blood Mononuclear Cells to Treat Rats With Acute Myocardial Infarction
}

\section{Hang Xiang ( $\sim$ mailbox9999@126.com )}

PLAGH: Chinese PLA General Hospital https://orcid.org/0000-0003-2764-4458

\section{Tianyuan Xiang}

Eli and Edythe Broad CIRM Center for Regenerative Medicine and Stem Cell Research at USC, Los Angeles, CA 90033. Health Management Institute, Chinese PLA General Hospital, Beijing 100853, China Hongxia Zhang

Eli and Edythe Broad CIRM Center for Regenerative Medicine and Stem Cell Research at USC, Los Angeles, CA 90033

\section{Ann Xu}

Eli and Edythe Broad CIRM Center for Regenerative Medicine and Stem Cell Research at USC, Los Angeles, CA 90033

\section{Matthew John Horwedel}

Division of Engineering in Medicine, Brigham and Women's Hospital, Harvard Medical School.

Cambridge, MA 02139

\section{Qiang Zeng}

Health Management Institute, Chinese PLA General Hospital, Beijing 100853, China

\section{Yang Li}

Department of Cardiology, Chinese PLA General Hospital, Beijing 100853, China

\section{Research}

Keywords: adipose derived mesenchymal stem cells, cord blood mononuclear cells, co-transplantation, hypoxic precondition, myocardial infarction

Posted Date: September 29th, 2020

DOl: https://doi.org/10.21203/rs.3.rs-80997/v1

License: (c) (i) This work is licensed under a Creative Commons Attribution 4.0 International License. Read Full License 


\section{Abstract}

\section{Background}

Human adipose derived mesenchymal stem cells (ASCs) are ideal candidates for the treatment of acute myocardial infarction (AMI), due to their favorable availability and regenerative potential. However, in vivo studies showed that ASCs are not resilient at the infarcted area, for a shortage of blood and oxygen supply.

Material and methods

To solve the problem of living in the hypoxic environment, we accommodated ASCs within the hypoxic condition. To enhance the capillary system, we combined the hypoxic pretreated ASCs (HP-ASCs) with cord blood mononuclear cells (CBMNCs), which have a great potential for neovascularization. We hypothesized that this combination system would improve the transplantation efficiency.

Results

In vitro study showed that HP-ASCs had a wide range of paracrine function, with the incretion growth factors and their receptors, which would support the cell survivals. In addition, HP-ASCs also gained potentials in hypoxic adaptation (increased expression of HO-1 and SDF-1), as well as homing and immigrating abilities (CXCR4, ICAM-1 and ICAM-2). In vivo studies showed that, 30 days after transplantation in AMI rats, the HP-ASCs group had a better improvement in cardiac function; reduction of the infarct size; and decrease of ASCs death than the other groups (HP-ASCs > HP-ASCs + CBMNCs $\geqq$ CBMNCs $>$ PBS $)(p<0.05)$. However, the combined group of HP-ASCs and CBMNCs had more significant angiogenesis than the other groups (HP-ASCs + CBMNCs > CBMNCs $>$ HP-ASCs $>$ PBS $)(p<0.05)$.

Conclusions

HP-ASCs alone had a greater potential in improving cardiac function in AMI rats. However, the combination of HP-ASCs and CBMNCs had a better result in angiogenesis.

\section{Background}

Myocardial infarction (MI) is a life-threatening emergency which causes hospitalization and life span reduction in US and worldwide [1]. The standard treatment of $\mathrm{Ml}$, including catheterization and medication, has shown significant improvement in outcomes. However, the damaged heart tissues can only be repaired with scars, which lost the myocardium characters of conductivity and contractility. Consequently, the fibrotic scar leads to a chronic process of cardiac remodeling, which results in compromised ventricular performance and chronic heart failure. The positive correlation between the size of infarction and mortality urged us to find a new treatment approach for heart regeneration [2]. Physiologically, the hearts of new-born babies have partial regenerative potential through the proliferation of pre-existing cardiomyocytes (CMs), but this does not exist in adults [3]. Recently, numerous studies 
reported that stem/ progenitor cells can be used for the treatment of ischemic heart diseases $[4,5]$. Among those, adipose-derived stromal cells (ASCs) have shown encouraging outcomes in clinical trials $[6,7]$. ASCs have more priorities than bone marrow stem cells for clinical use $[8,9]$, for their large quantities in isolation and minimal invasion, as well as high yield of progenitor cells per volume.

However, there are still some obstacles in improving ASCs survivals after transplantation, which result from regional hostile microenvironment. The field is not suitable for transplanted cells to survive, as it is surrounded by necrotic cells and inflammatory cells that increase the oxidative stress. As a consequence, stem cells generally display limited survival and low retention rate in injured tissues, reducing the benefit of their therapeutic effects[10]. Therefore, we need to solve the problem of hypoxia adaption and blood supply, in order to elongate the cell lives in vivo.

To overcome the obstacle of hypoxia adaption, various precondition methods (e.g., hypoxia, heat shock, and exposure to oxidative stress) were used to accommodate the cells in vitro[11]. Hypoxia was a feasible and potential way to adapt cells before they were transplanted [12]. Exposure to a sub-lethal hypoxic would significantly increase the tolerance and regenerative properties of stem/progenitor cells, resulting in marked protective effects against insults in the ischemic attack [13].

\section{The aim}

To establish a conducive vascular environment, scientists developed different co-transplantation systems that interacts synergistically to form stable vessels [14]. Human umbilical cord blood mononuclear cells (UCMNCs) have generated significant attention in regenerative medicine for their efficacy in treating ischemic diseases $[15,16]$. And UCMNCs have been used with different types of stem cells in animal models [17]. Therefore, we hypothesized that co-transplantation of ASCs with UCMNCs would raise the survival efficacy for the damaged tissue and seeded stem cells.

\section{Materials And Methods}

\section{Ethical approval}

All the animal experiments were performed according to the Federation for Laboratory Animal Science Association's guidelines and approved by the Animal Care Committee of the PLA General Hospital (E2018-06-06).All experiments were carried out in compliance with the Helsinki Declaration. ASCs were obtained from a healthy man who underwent a plastic abdominal surgery, and CBMNCs were isolated from cord blood of a normally delivered female baby. Both of them were obtained from the donors with informed consent according to the institutional guidelines under the approved protocol. The cord blood was collected and processed with the approval of the 'Chinese PLA General Hospital Institutional Review Board' (L2018-12-03) and manufactured to mononuclear cells according to our good manufacturing practice (GMP) process in the Human Cell Therapy Laboratory, Chinese PLA General Hospital, China. 


\section{Isolation and Identification of Human ASCs}

Subcutaneous abdominal adipose tissues were obtained from a healthy male who underwent a liposuction surgery. Adipose tissue was washed in phosphate-buffered saline (PBS) and minced, followed by digestion in $5 \mathrm{ml}$ of type I Collagenase $(1 \mathrm{mg} / \mathrm{ml}$ in $1 \%$ bovine serum albumin(BSA)/Hank's balanced saline solution; Life Technologies Japan) for 40 minutes at $37^{\circ} \mathrm{C}$ using a gentle MACS Dissociator (MiltenyiBiotec K.K., Tokyo, Japan) according to the manufacturer's instructions. The digested tissue was filtered through a 40- $\mu \mathrm{m}$ cell strainer (BD Falcon, Tokyo, Japan) and centrifuged at $450 \mathrm{~g}$ for 10 minutes. The supernatant containing adipocytes and debris were discarded. Pelleted cells were rinsed twice with PBS, and then planted on the petri dishes with a density of $\sim 2.0 \times 10^{5} / \mathrm{cm}^{2}$. ASCs were cultured according to the standard protocol, with our modified media in Dulbecco's modified Eagle's medium (DMEM)-F12 (Gibco), supplemented with 10\% FBS (HyClone), 100U/ml penicillin, and 100 $\mathrm{gg} / \mathrm{ml}$ streptomycin (Biolot). ASCs were subcultured after attaining 70-80\% confluency. Passage 3-4 cells were used in the study.

ASCs were identified with flowcytometry analysis by incubation with primary antibodies for 40 min at 4 ${ }^{\circ} \mathrm{C}$ in phosphate-buffered saline (PBS) supplemented with $2 \% \mathrm{FBS}$ and $2 \mathrm{mM}$ ethylenediaminetetraacetic acid (EDTA). The following direct conjugated antibodies (BD Pharmingen ${ }^{\mathrm{TM}}$ ) were used: anti-human (PECD34, PerCP-CD45, PE-CD90, APC-CD44, PE-CD73, and PE-CD105). All staining was controlled with appropriate isotope control antibodies. Analysis was performed on a SORP LSRII (Becton Dickinson) equipped with five lasers and data were collected with FACS DIVA software. Analysis was performed using FlowJo ${ }^{\text {TM }}$ 10.0.8 (Treestar, Ashland, OR). All measurements were performed with three biological replicates.

Linage differentiation tests for osteogenesis, adipogenesis and chondrogenesis was performed as described before $[18,19]$. Osteogenic differentiation was evaluated by cellular alkaline phosphatase (ALP) activity (Alkaline Phosphatase kit, 86R; Sigma-Aldrich). Adipogenesis was confirmed by Oil red 0 staining of intracellular lipids, and chondrogenesis was confirmed by Alcian blue staining [19].

\section{Hypoxia Precondition of ASCs}

Hypoxic treatment protocol was referred as previously reported with some modification [20]. A total of $3 \mathrm{x}$ $10^{6}$ ASCs $\left(\mathrm{P}_{3}\right)$ were seeded on a T75 flask and cultured at $2 \% \mathrm{O}_{2}$ (hypoxia) in a ProOx-C-chamber system (Biospherix, Redfield, NY), in comparation with the ambient oxygen tension $21 \% \mathrm{O}_{2}$ (normoxia). Seventytwo hours later, cells were harvested for RNA expression analysis (Supplement Table 1).

\section{Cord blood mononuclear cells (CBMNCs) Isolation}

Isolation of CBMNCs was performed as reported before [21]. In brief, $35 \mathrm{ml}$ of fresh cord blood was collected from a healthy woman with an uncomplicated delivery. The blood was mixed with $7 \mathrm{ml}(1: 5)$ Hetastarch solution (HetaSep ${ }^{\text {TM }}$, STEM CELL TECH, US), and incubated at $37^{\circ} \mathrm{C}$ for $30 \mathrm{~min}$. Then, the cells 
in the floating layer were transferred to another tube, mixed with normal saline (NS) to 50ml, and centrifuged for 10min (1500rpm). After having been washed for 2 times, the cord blood cells were mixed with a $5 \mathrm{ml}$ lymphocyte separation medium (50494 LSM $^{\circledR}$, Cappel $^{\mathrm{TM}}$, Shanghai), and centrifuged for $20 \mathrm{~min}$ (1500rpm). The thin layer of mononuclear cells was extracted carefully and washed 2 times. Cell viability was evaluated with a trypan blue exclusion test, and cell concentration was brought to 1.5$2.5 \times 10^{6}$ cells $/ \mathrm{ml}$ and used within $30 \mathrm{~min}$.

\section{Surgical Procedure and Transplantation}

Female Wistar rats (250-300g) were intubated under general anesthesia with 4\% chloral hydrate (4 $\mathrm{mg} / \mathrm{kg}$, intraperitoneally injection) and ventilated with room air by a small animal ventilator (SAR-830/AP, CWE, US). Myocardial infarction was induced by permanent ligation of the left anterior descending coronary artery with a 6-0 silk suture. Successful performance of coronary occlusion was verified by blanching of the myocardium distal to the coronary ligation [22]. Stem cells or PBS were transplanted immediately after ligation of the left anterior descending coronary artery. Transplanted groups were divided into 4 groups: (1) HP-ASCs group ( $n=10,1 \times 10^{6}$ ASCs); (2) HP-ASCs + CBMNCs group ( $n=10$,

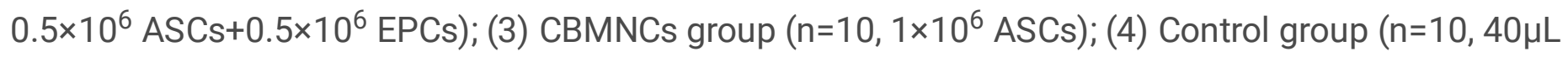
PBS). A total amount of $40 \mu \mathrm{L}$ mixture was directly injected into 5 spots around the ischemic region.

\section{Measurement of Heart Function}

Echocardiography (Vevo770; Visualsonics, Toronto, ON, Canada) was performed at 0d and 30d after myocardial ischemia. Rats were anesthetized with $4 \%$ chloral hydrate ( $40 \mathrm{mg} / \mathrm{kg}$, intraperitoneally), and imaged in the supine position at the fourth and fifth intercostal space with a 710B transducer. Both 2D and M-mode images were used for measurements, and images were later analyzed by a trained blind reader using the cardiac analysis software (VisualSonics, version 2.2.3). The following variables are measured: ejection fraction (EF), fractional shortening (FS), stroke volume (SV), heart rate (HR), and left ventricle posterior wall thickening (LVPW) were measured.

\section{Infarct Size Measurement}

All the hearts were harvested at $30 \mathrm{~d}$ and embedded in optimal cutting temperature (OCT) compound (Sakura Finetek USA Inc, Torrance, Calif). The infarct and peri-infarct regions were cut into three transverse sections then and stained by Masson trichrome and hematoxylin-eosin (HE). The stained sections were measured and calculated for the average ratio of fibrosis area (blue) to the entire LV area (percentage of fibrosis area), and the average ratio of the reduced LV wall thickness in the scarred area to the intact LV wall thickness from three different sites in each wall (LV wall thinning \%). For each slice, 10 randomly selected fields were captured $(\times 100)$ and images were digitized and analysed with a digital image analyser (MIQAS, Qiuwei Co, China). 


\section{Living ASCs Cell Count and Vessel Count in Necrotic Area}

To count the living ASCs in heart sections, we used anti-human SRY antibody (Cat\#MA5-17181, 1:200, Invitrogen, US) to trace the ASCs cells (ASCs used were only from human male)[23]. Six fields per heart section were randomly chosen and photographed under 40× magnification with a fluorescent microscope, and live cells (cells $/ \mathrm{mm}^{2}$ ) were counted in every tenth heart section across the entire region of interest.

For vascular counting, we used anti-human CD31 (Cat\#ab32457, 1:200, Abcam, Shanghai) to stain the newly formed capillaries. The number of capillaries was counted under a light microscope (magnification $\times 250$, OLYMPUS BH2, Japan) for 10 random fields in each transverse slice and presented as the mean number of blood vessels per unit area (number $/ \mathrm{mm}^{2}$ ). Both of these performances were repeated in 8 separate sections per heart. Two independent observers were blinded to the identity of the tissues.

\section{Statistical Analysis}

Statistics were performed using SPSS 17.0 Software. Data are expressed as Mean \pm Standard Error. Statistical comparisons were made using an unpaired $t$-test or one-way analysis of variance followed by Bonferroni multiple comparison post hoc tests where appropriate. The results were considered statistically significant when $P<0.05$.

\section{Results}

Characterization of ASCs and Differentiation

Morphology of ASCs was homogenously spindle-like after three passages (Fig.1A). Over $90 \%$ of the population expressed the MSC-specific surface markers CD90 (+), CD105 (+), CD73 (+), CD44 (+), and were negative for hematopoietic stem cell and endothelial surface marker CD45(-),CD34(-) (Fig.1B).

Differentiation tests showed that cultured ASCs (P3) have a strong potential of differentiation with osteogenesis, adiposegenesis and chondrogenesis, which were specific characteristics for mesenchymal stem cells (Fig.1A).

HP-ASCs Gene Expression after Hypoxia Pre-treatment in Vitro

HP-ASCs displayed a strong adaptation for hypoxia after 72 hours of hypoxic treatment, by increasing the expression of Heme Oxygenase-1 (HO-1) and Stromal cell Derived Factor-1 (SDF-1) (Fig.2A), as well as enhanced cell migration (CXCR4) and adhesion (ICAM-1and ICAM-2) potential(Fig.2B). HP-ASCs also had boosted expression of growth factors and their receptors (EGF/EGFR, IGF-1/IGFR2; TGF(a, $\beta$ )/TGF- $\beta$ (R1, R2); VEGF-a/VEGF(R2, R3); FGF (R2, R3, R4) (Fig.2C-G). However, it did not show any evidence that HPASCs had been differentiation toward myocardocytes (Fig 2H). 
Cardiac function and haemodynamics after transplantation

Cardiac function was compared before and after cell transplantation ( $0 \mathrm{~d}$ and $30 \mathrm{~d}$ ). The results showed that there was no difference between these four groups before transplantation. At 30d, HP-ASCs group had better functional improvement in EF ( $\triangle \mathrm{EF}: 8.7 \pm 11.56 \%)$, FS $(\Delta \mathrm{FS}:-4.7 \pm 8.95)$, LVPWs ( $\Delta$ LVPWs: $8.70 \pm 11.56 \%)$, SV $(\Delta S V: 47.84 \pm 19.27 \%)$ and HR $(\Delta H R:-8.15 \pm 10.88 \%)(p<0.05)$. It is noticeable that the improvements in the combination group (ASCs + CBMNCs) and CBMNCs group were very similar $(p>0.05)$, both of which were better than the PBS group $(p<0.05)$ (Fig.3A-E).

Myocardial fibrosis

Masson's trichrome staining showed patchy areas of fibrosis in the heart tissue in all groups after cell transplantation (4A-B). The length of fibrosis in heart tissue of the HP-ASCs group (38.81 $\pm 5.64 \%)$ was less than the other 3 groups $(p<0.05)$.No significant difference was detected between the combination group $(42.82 \pm 5.33 \%)$ and the CBMNCs group $(43.46 \pm 4.54 \%)(p>0.05)$, both of which were less than the control group $(48.92 \pm 7.89 \%)(p<0.05)$ (Fig.4C).

The average of the LV wall scar thickness in HP-ASCs group was $934.85 \pm 78.21 \mu \mathrm{m}$, which was greater than the combination group $(751.57 \pm 85.94 \mu \mathrm{m})$, CBMNCs group $(822.46 \pm 114.54 \mu \mathrm{m})$ and PBS group $(694.82 \pm 157.61 \mu \mathrm{m})(p<0.05)$. Accordingly, the reduced percentage of LV wall thickness in HP-ASCs group was less than the other 3 groups $(p<0.05)$ (Fig.4D).

Live ASCs in the infarct area

Stained with anti-human SRY antibody, live ASCs cells were only detectable in HP-ASCs group and HPASCs + CBMNCs group (Fig.5A). The result showed that HP-ASCs group had great numbers of live cells (37.43 \pm 12.68 cells $/ 100$ nucleus). However, the combination group ( $21.51 \pm 7.82$ cells $/ 100$ nucleus) had a much lower live cell density than the HP-ASCs group $(p<0.05)$ (Fig.5C).

Capillary density

To assess the neovascularization activity, we stained heart sections with the endothelial cell marker CD31 (Fig.5B). The CBMNCs group had the highest capillary density $\left(128.2 \pm 15.25 / \mathrm{mm}^{2}\right)$, which was significantly greater than the combination group $\left(98.59 \pm 13.41 / \mathrm{mm}^{2} ; p<0.05\right)$, HP-ASCs group $\left(59.46 \pm 9.75 / \mathrm{mm}^{2} ; p<0.05\right)$, and the control group (25.94 $\left.\pm 8.46 / \mathrm{mm} 2 ; p<0.05\right)$ (Fig.5D).

\section{Discussion}

Hypoxia pretreatment has been demonstrated to be an effective way to accommodate the stem cells before transplantation[11]. It is also an effective way to enhance MSCs survival in myocardial ischemiareperfusion injury [24], as well as promote angiogenesis and neurogenesis in rat ischemic brain models [25]. To understand its mechanism, we analyzed the gene expression of HP-ASCs in vitro, which showed an enriched paracrine profiles. The highly raised growth factors (EGF, VEGF, PDGF, TGF- $\beta$, FGF-2 and IGF- 
1) have been demonstrated to be essential for cell survival and capillary buildup [26]. we also found that HP-ASCs can facilitate the reparation of the ischemic area by potentiating the chemotactic effects, based upon the evidence of up regulation of migration (CXCL12) and adhesion (ICAM-1 and ICAM-2), which had been reported in previous studies [24].These findings were in according with the previous studies which demonstrated that preconditioned stem/progenitors cells increased cell survival, enhanced paracrine effects and improved homing to the lesion site[13]. Also, these preconditioned cells helped to suppress inflammatory factors and immune responses after transplantation[11]. Some studies reported that ASCs primed with hypoxia and inflammation could enhance cardiomyocyte proliferation rate [12]. However, we did not find evidence for myocardial differentiation in HP-ASCs in vitro (negative with myocardiocyte markers: a-actin, MYH6, NKX2.5, CX43, GATA-4) (data not shown). This inconformity was probably resulted from the different pretreatment conditions and culturing periods.

Combined transplantation has been explored for treatment in the past few years, but it still remains paradoxical because not all of the combinations would work $[15,16,27]$. Studies have reported that some stem/progenitor cells would improve the efficacy of MSCs/ASCs when they were co-transplantated. For example, endothelial progenitor cells (EPCs), potentially proangiogenic cells, would promote vascular buildup when combined with MSCs [28]. However, in a meta-analysis, no significant difference in angiogenesis was found in AMI rats, comparing the EPCs groups and MSCs+ EPCs groups, even though the latter had a better improvement in the cardiac function [17]. Different from the previous studies, we observed enhanced angiogenesis in the combination group, but not finding advantages of cotransplantation in improving cardiac function or reducing myocardial fibrosis, as well as elongating ASCs survival.

There might be a few reasons for the failure of the co-transplantation. First, CBMNCs were a mixture of stem/progenitor cells, which consists of endothelial progenitor cells (EPCs)[29], hematopoietic stem/ progenitor cells (HSPCs)[30], and endothelial colony-forming cells (ECFCs)[14]. Though some components can work synergistically with ASCs, while others may not [27]. Further studies are still needed to identify the fractions that impede the cell-cell interactions.

The second reason for the impediment of the combined effect was attributed to heterogeneity, which resulted from various factors, such as differences in the amounts and ratios of these two types of cells, organization source, measurement time and so on [17]. For instance, cell ratios may play an important role for determining the ultimate result in reparation, as these two types of cells may have a strong competition for oxygen and nutrition. In a previous study, scientists screened a serial of ratios between HSCs and MSCs (1:0, 1:1, 1:2, 1:4, 1:8 and 1:16), which fixed an optimal ratio of 1:8-1:16 to regain the hemopoietic function in NOD/SCID mice [31]. However, people tend to use 1:1 ratio with different dosage to treat AMI, which showed various efficiency [17]. Therefore, further studies are still needed to explore the optimal conditions for co-transplantation.

Another reason for the impediment of the combined effect was that the growth factors secreted by ASCs might be deployed by CBMNCs for their survival and new vessels formation, rather than promoting ASCs' 
survivals. It has been demonstrated by many studies, as well as by this study, that HP-ASCs had an enriched paracrine functions before they were transplanted [26, 32, 33]. ASCs would support other types of cells (e.g. HSPCs) for their viability and proliferation, through direct/ paracrine cell-to-cell interactions $[34,35]$. In addition, ASCs can also upregulate the adhesion molecule and extracellular matrix genes in HSPCs, which was good for the latter to anchor and survive in the local area [36].All aforementioned evidence demonstrated that the paracrine factors that secreted by ASCs might be used by CBMNCs for survival and function when they are co-transplanted simultaneously. So, we need to find new strategies to improve the treatment efficacy. A plausible method is that transplanting the different type of cells in a sequential way, i.e. transplanting CBMNCs before ASCs, so that new vessels would support the later to survive. However, the intervals need to be determined, which is neither too close to influence individual cell's survival, nor too far to lower the treatment efficiency.

\section{Limitations}

However, we still have some limitations with our study. First, we should select the effective component that will work with ASCs synergistically by a co-culture system. Second, we need to explore the optimal intervals for successive transplantation, in order to enable the vascular buildup before the injection of ASCs. Third, we should also investigate the cross-talk between the implanted cells and the host cells. In the future studies, we would trace different types of cells with different labeled colors and carry out the experiment with organ-on-chip models.

\section{Conclusion}

In all, HP-ASCs were effective in improving cardiac function and reducing the size of infarcted myocardium in rats with AMI. When combined with CBMNCs, there would be more increase in angiogenesis, but no significant promotion for ASCs survival.

\section{Declarations}

\section{Ethics approval and consent to participate}

Not applicable.

\section{Consent for publication}

All the authors were consent for publication.

\section{Data Availability Statement}

The data that support the findings of this study are available from the corresponding authors upon request. 


\section{Competing interests}

The authors declare that they have no competing interests.

\section{Funding Sources}

This study was supported by the National Natural Science Foundation of China (No.81870249) and China Postdoctoral Science Foundation Grant (No.2018M633675).

\section{Author Contributions}

Conception and design of the study: QZ, YL. Acquisition of data: HX, TYX. Analysis and interpretation of data: HX, HXZ, AX. Drafting or revising the manuscript: HX, MJH. All authors have approved the final article.

\section{Declaration of Competing Interest}

The authors have no commercial, proprietary, or financial interest in the products or companies described in this article.

\section{Acknowledgements}

The authors are grateful to the grants which supports our research projects.

\section{Authors' information}

${ }^{1}$ Department of Cardiology, Chinese PLA General Hospital, Beijing, China, 100853. ${ }^{2}$ Eli and Edythe Broad CIRM Center for Regenerative Medicine and Stem Cell Research at USC, Los Angeles, CA $90033 .{ }^{3}$ Health Management Institute, Chinese PLA General Hospital, Beijing 100853, China. ${ }^{4}$ Division of Engineering in Medicine, Brigham and Women's Hospital, Harvard Medical School. Cambridge, MA 02139.

\section{References}

1. Mozaffarian D, Benjamin EJ, Go AS, Arnett DK, Blaha MJ, Cushman M, de Ferranti S, Despres JP, Fullerton HJ, Howard VJ et al: Heart disease and stroke statistics-2015 update: a report from the American Heart Association. Circulation. 2015; 131:e29-322.

2. Yoshida K, Gould KL: Quantitative relation of myocardial infarct size and myocardial viability by positron emission tomography to left ventricular ejection fraction and 3-year mortality with and without revascularization. Journal of the American College of Cardiology. 1993; 22:984-997.

3. Mollova M, Bersell K, Walsh S, Savla J, Das LT, Park SY, Silberstein LE, Dos Remedios CG, Graham D, Colan S et al: Cardiomyocyte proliferation contributes to heart growth in young humans. Proceedings 
of the National Academy of Sciences of the United States of America. 2013; 110:1446-1451.

4. Wollert KC, Meyer GP, Lotz J, Ringes-Lichtenberg S, Lippolt P, Breidenbach C, Fichtner S, Korte T, Hornig B, Messinger D et al: Intracoronary autologous bone-marrow cell transfer after myocardial infarction: the BOOST randomised controlled clinical trial. Lancet (London, England). 2004; 364:141148.

5. Hare JM, Fishman JE, Gerstenblith G, DiFede Velazquez DL, Zambrano JP, Suncion VY, Tracy M, Ghersin E, Johnston PV, Brinker JA et al: Comparison of allogeneic vs autologous bone marrowderived mesenchymal stem cells delivered by transendocardial injection in patients with ischemic cardiomyopathy: the POSEIDON randomized trial. Jama. 2012; 308:2369-2379.

6. Oguz E, Ayik F, Ozturk P, Engin C, Nalbantgil S, Yagdi T, Ozbaran M: Long-term results of autologous stem cell transplantation in the treatment of patients with congestive heart failure. Transplantation proceedings. 2011; 43:931-934.

7. Losordo DW, Schatz RA, White CJ, Udelson JE, Veereshwarayya V, Durgin M, Poh KK, Weinstein R, Kearney M, Chaudhry M et al: Intramyocardial transplantation of autologous CD34+ stem cells for intractable angina: a phase I/lla double-blind, randomized controlled trial. Circulation. 2007; 115:3165-3172.

8. Argentati C, Morena F, Bazzucchi M, Armentano I, Emiliani C, Martino S: Adipose Stem Cell Translational Applications: From Bench-to-Bedside. International journal of molecular sciences. 2018; 19.

9. Minteer DM, Marra KG, Rubin JP: Adipose stem cells: biology, safety, regulation, and regenerative potential. Clinics in plastic surgery. 2015; 42:169-179.

10. Lo EH, Wang X, Cuzner ML: Extracellular proteolysis in brain injury and inflammation: role for plasminogen activators and matrix metalloproteinases. Journal of neuroscience research. 2002; 69:1-9.

11. Sart S, Ma T, Li Y: Preconditioning stem cells for in vivo delivery. BioResearch open access. 2014; 3:137-149.

12. Przybyt E, Krenning G, Brinker MG, Harmsen MC: Adipose stromal cells primed with hypoxia and inflammation enhance cardiomyocyte proliferation rate in vitro through STAT3 and Erk1/2. Journal of translational medicine. 2013; 11:39.

13. Hu X, Yu SP, Fraser JL, Lu Z, Ogle ME, Wang JA, Wei L: Transplantation of hypoxia-preconditioned mesenchymal stem cells improves infarcted heart function via enhanced survival of implanted cells and angiogenesis. The Journal of thoracic and cardiovascular surgery. 2008; 135:799-808.

14. Lin RZ, Moreno-Luna R, Li D, Jaminet SC, Greene AK, Melero-Martin JM: Human endothelial colonyforming cells serve as trophic mediators for mesenchymal stem cell engraftment via paracrine signaling. Proceedings of the National Academy of Sciences of the United States of America. 2014; 111:10137-10142.

15. Oommen S, Yamada S, Cantero Peral S, Campbell KA, Bruinsma ES, Terzic A, Nelson TJ: Human umbilical cord blood-derived mononuclear cells improve murine ventricular function upon 
intramyocardial delivery in right ventricular chronic pressure overload. Stem cell research \& therapy. 2015; 6:50.

16. Henning RJ, Abu-Ali H, Balis JU, Morgan MB, Willing AE, Sanberg PR: Human umbilical cord blood mononuclear cells for the treatment of acute myocardial infarction. Cell transplantation. 2004; 13:729-739.

17. Sun K, Zhou Z, Ju X, Zhou Y, Lan J, Chen D, Chen H, Liu M, Pang L: Combined transplantation of mesenchymal stem cells and endothelial progenitor cells for tissue engineering: a systematic review and meta-analysis. Stem cell research \& therapy. 2016; 7:151.

18. Wystrychowski W, Patlolla B, Zhuge Y, Neofytou E, Robbins RC, Beygui RE: Multipotency and cardiomyogenic potential of human adipose-derived stem cells from epicardium, pericardium, and omentum. Stem cell research \& therapy. 2016; 7:84.

19. Bwalya EC, Kim S, Fang J, Wijekoon HMS, Hosoya K, Okumura M: Effects of pentosan polysulfate and polysulfated glycosaminoglycan on chondrogenesis of canine bone marrow-derived mesenchymal stem cells in alginate and micromass culture. The Journal of veterinary medical science. 2017; 79:1182-1190.

20. Hsiao ST, Lokmic Z, Peshavariya H, Abberton KM, Dusting GJ, Lim SY, Dilley RJ: Hypoxic conditioning enhances the angiogenic paracrine activity of human adipose-derived stem cells. Stem cells and development. 2013; 22:1614-1623.

21. Maslova EV, Andreeva ER, Andrianova IV, Bobyleva PI, Romanov YA, Kabaeva NV, Balashova EE, Ryaskina SS, Dugina TN, Buravkova LB: Enrichment of umbilical cord blood mononuclears with hemopoietic precursors in co-culture with mesenchymal stromal cells from human adipose tissue. Bulletin of experimental biology and medicine. 2014; 156:584-589.

22. li M, Nishimura H, Iwakura A, Wecker A, Eaton E, Asahara T, Losordo DW: Endothelial progenitor cells are rapidly recruited to myocardium and mediate protective effect of ischemic preconditioning via "imported" nitric oxide synthase activity. Circulation. 2005; 111:1114-1120.

23. Zhang X, Wei M, Zhu W, Han B: Combined transplantation of endothelial progenitor cells and mesenchymal stem cells into a rat model of isoproterenol-induced myocardial injury. Archives of cardiovascular diseases. 2008; 101:333-342.

24. Tang YL, Zhu W, Cheng M, Chen L, Zhang J, Sun T, Kishore R, Phillips MI, Losordo DW, Qin G: Hypoxic preconditioning enhances the benefit of cardiac progenitor cell therapy for treatment of myocardial infarction by inducing CXCR4 expression. Circulation research. 2009; 104:1209-1216.

25. Chen J, Yang Y, Shen L, Ding W, Chen X, Wu E, Cai K, Wang G: Hypoxic Preconditioning Augments the Therapeutic Efficacy of Bone Marrow Stromal Cells in a Rat Ischemic Stroke Model. Cellular and molecular neurobiology. 2017; 37:1115-1129.

26. Li X, Ma T, Sun J, Shen M, Xue X, Chen Y, Zhang Z: Harnessing the secretome of adipose-derived stem cells in the treatment of ischemic heart diseases. Stem cell research \& therapy. 2019; 10:196.

27. Hong SJ, Kihlken J, Choi SC, March KL, Lim DS: Intramyocardial transplantation of human adiposederived stromal cell and endothelial progenitor cell mixture was not superior to individual cell type 
transplantation in improving left ventricular function in rats with myocardial infarction. International journal of cardiology. 2013; 164:205-211.

28. Zigdon-Giladi H, Bick T, Lewinson D, Machtei EE: Co-transplantation of endothelial progenitor cells and mesenchymal stem cells promote neovascularization and bone regeneration. Clinical implant dentistry and related research. 2015; 17:353-359.

29. Suuronen EJ, Price J, Veinot JP, Ascah K, Kapila V, Guo XW, Wong S, Mesana TG, Ruel M: Comparative effects of mesenchymal progenitor cells, endothelial progenitor cells, or their combination on myocardial infarct regeneration and cardiac function. The Journal of thoracic and cardiovascular surgery. 2007; 134:1249-1258.

30. Noort WA, Kruisselbrink AB, in't Anker PS, Kruger M, van Bezooijen RL, de Paus RA, Heemskerk MH, Lowik CW, Falkenburg JH, Willemze R et al: Mesenchymal stem cells promote engraftment of human umbilical cord blood-derived CD34(+) cells in NOD/SCID mice. Experimental hematology. 2002; 30:870-878.

31. Kim DH, Yoo KH, Yim YS, Choi J, Lee SH, Jung HL, Sung KW, Yang SE, Oh WI, Yang YS et al: Cotransplanted bone marrow derived mesenchymal stem cells (MSC) enhanced engraftment of hematopoietic stem cells in a MSC-dose dependent manner in NOD/SCID mice. Journal of Korean medical science. 2006; 21:1000-1004.

32. Rehman J, Traktuev D, Li J, Merfeld-Clauss S, Temm-Grove CJ, Bovenkerk JE, Pell CL, Johnstone BH, Considine RV, March KL: Secretion of angiogenic and antiapoptotic factors by human adipose stromal cells. Circulation. 2004; 109:1292-1298.

33. Dai W, Hale SL, Kloner RA: Role of a paracrine action of mesenchymal stem cells in the improvement of left ventricular function after coronary artery occlusion in rats. Regenerative medicine. $2007 ; 2: 63-$ 68.

34. Andreeva ER, Andrianova IV, Gornostaeva AN, Gogiya BS, Buravkova LB: Evaluation of committed and primitive cord blood progenitors after expansion on adipose stromal cells. Cell and tissue research. 2018; 372:523-533.

35. Andreeva ER, Andrianova IV, Sotnezova EV, Buravkov SV, Bobyleva PI, Romanov YA, Buravkova LB: Human adipose-tissue derived stromal cells in combination with hypoxia effectively support ex vivo expansion of cord blood haematopoietic progenitors. PloS one. 2014; 10:e0124939.

36. Buravkova LB, Andreeva ER, Lobanova MV, Cotnezova EV, Grigoriev Al: The Differential Expression of Adhesion Molecule and Extracellular Matrix Genes in Mesenchymal Stromal Cells after Interaction with Cord Blood Hematopoietic Progenitors. Doklady Biochemistry and biophysics. 2018; 479:69-71.

\section{Figures}


A.
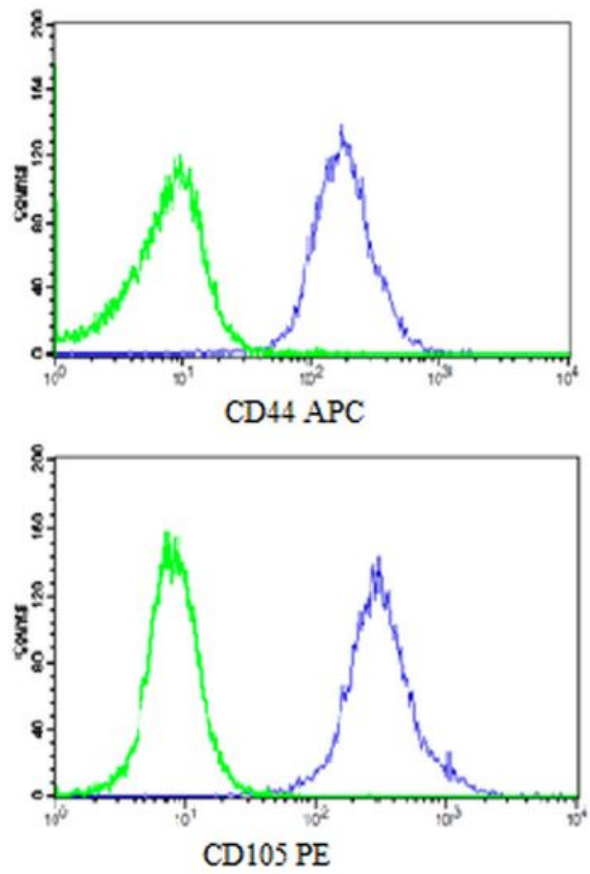

B.

Adiposegenesis

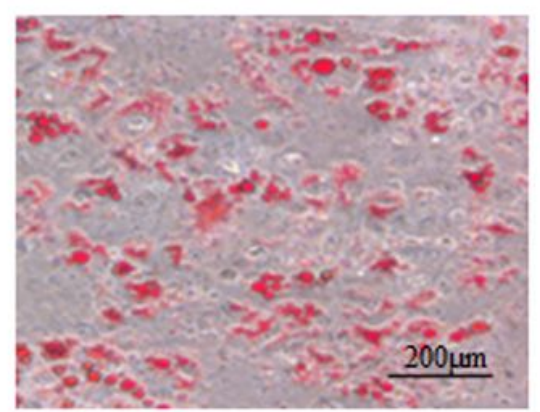

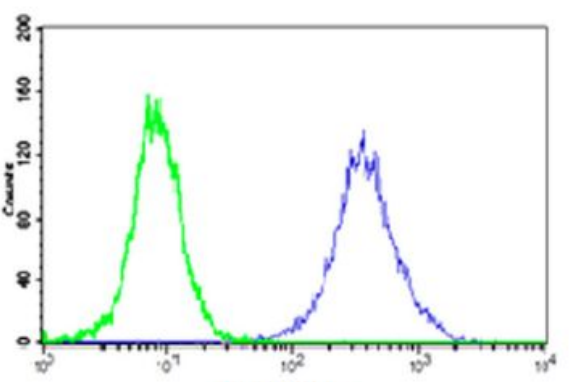

CD73 PE

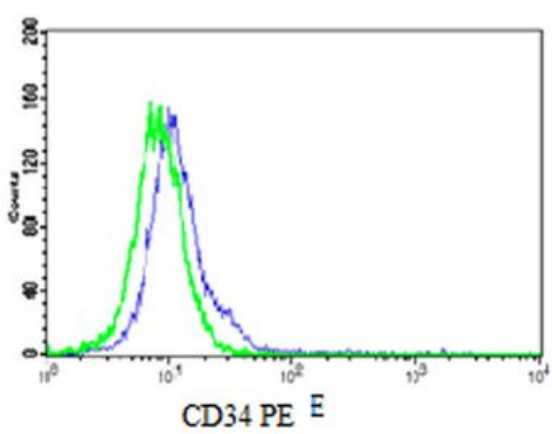

CD34 PE E

Osteogenesis

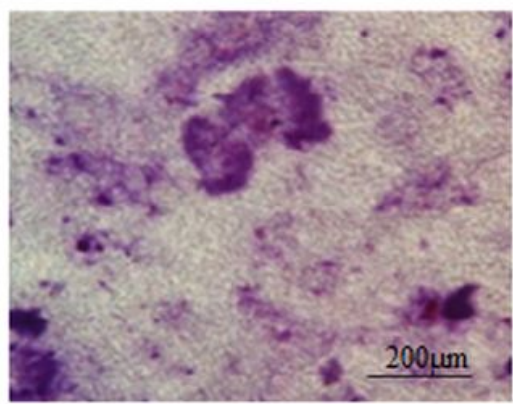

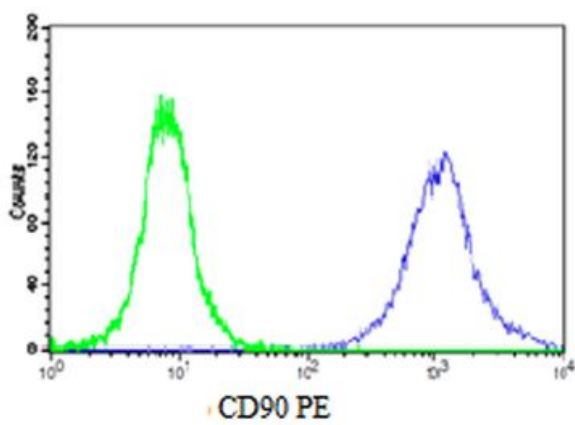

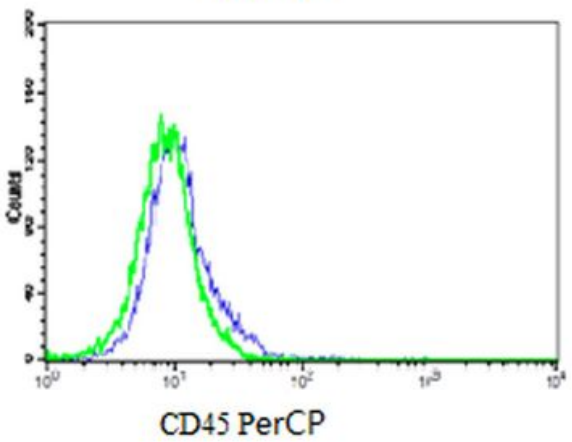

Chondrogenesis

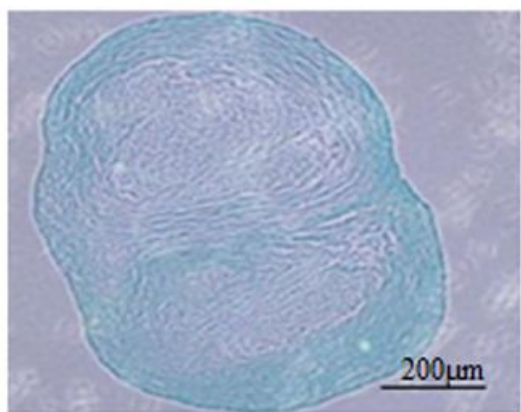

\section{Figure 1}

Surface markers and differentiation tests of ASCs. (A) Distribution of surface markers of ASCs was detected by flow cytometry. (B) Differentiation test for adiposegenesis (red oil staining, x40), osteogenesis (alkaline phosphatase staining, x40), and chondrogenesis (Alcian blue staining, x40) of ASCs. 

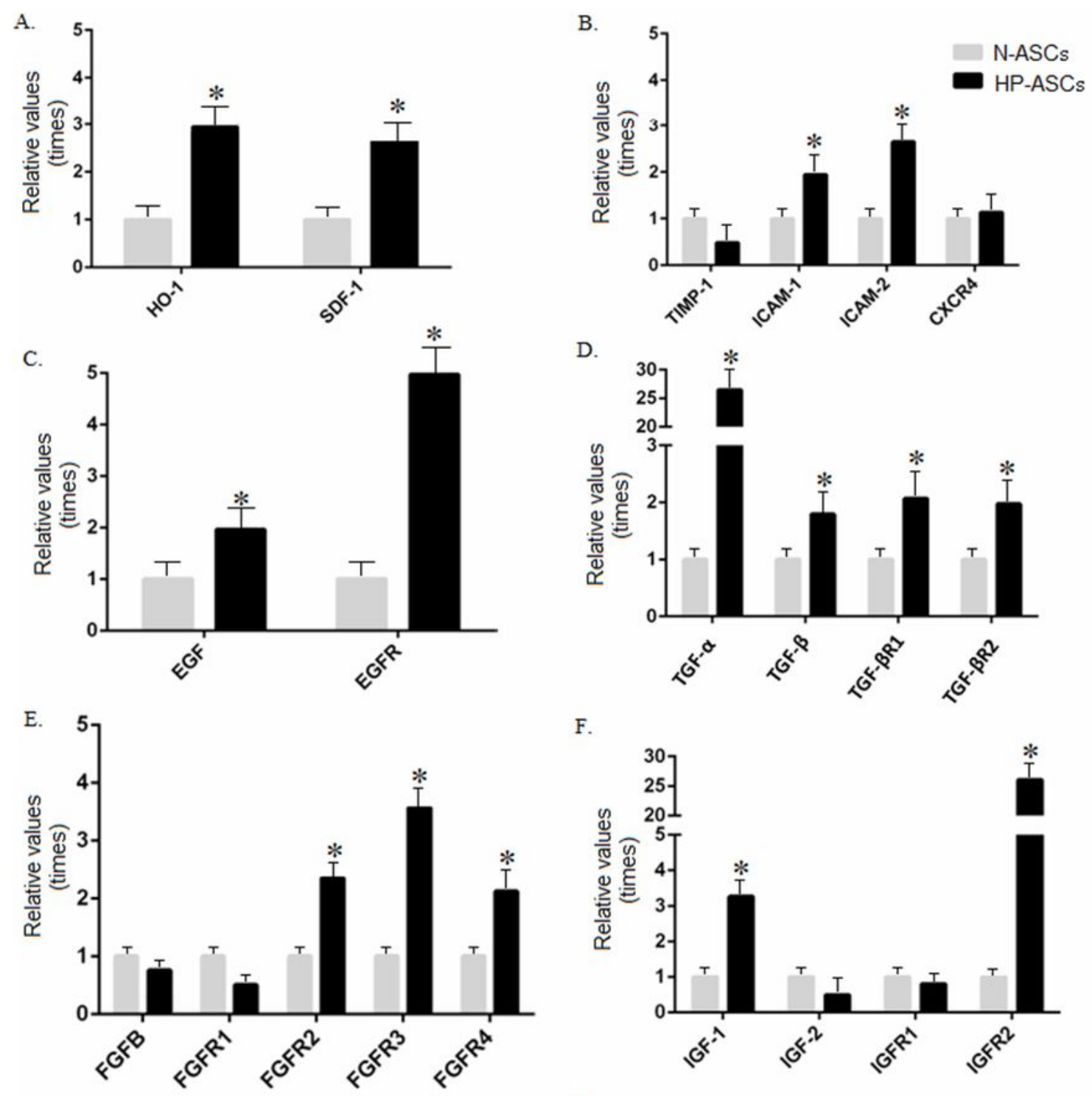

F.
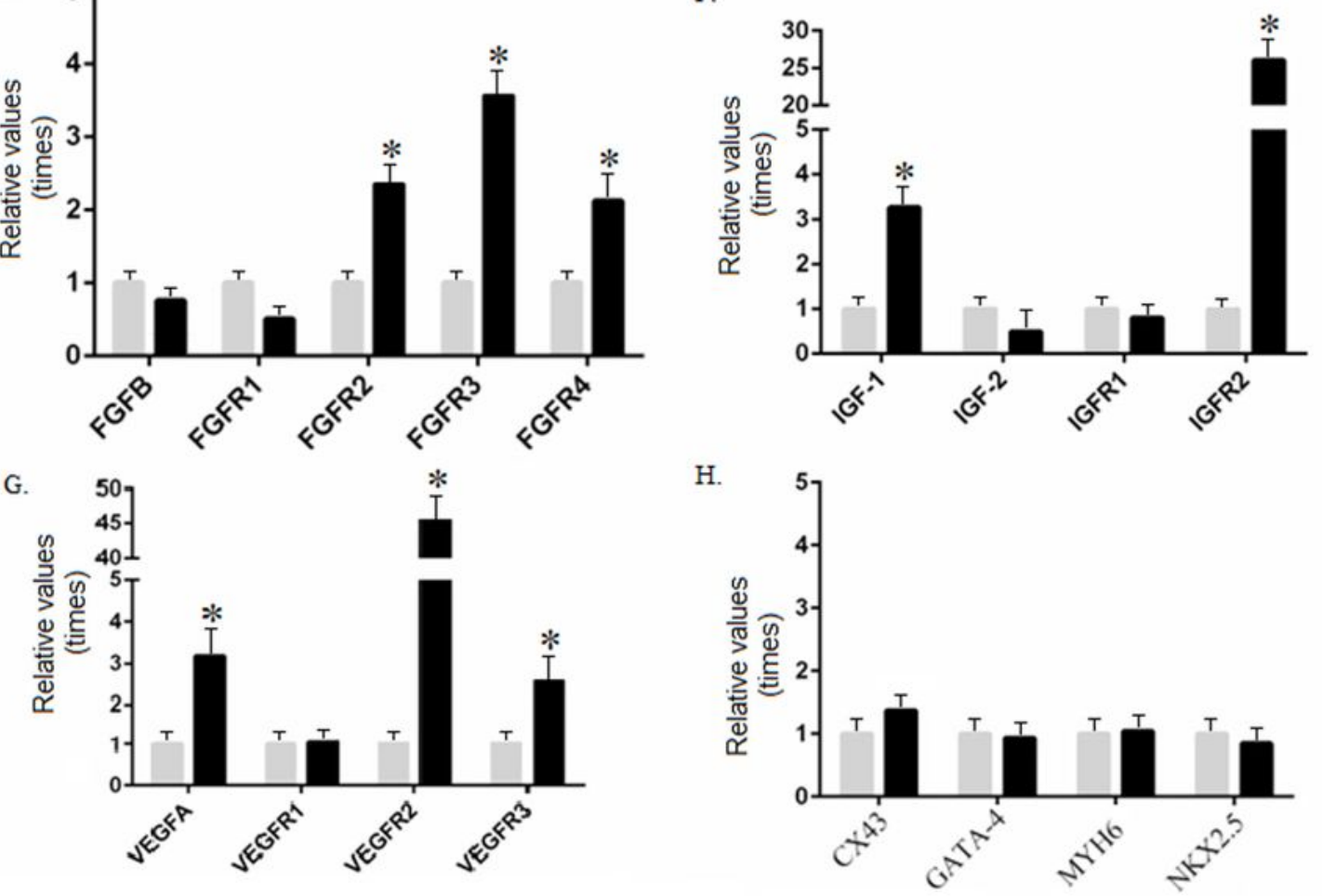

Figure 2

Gene expressions of HP-ASCs compared with N-ASCs. (A) Comparisons of HO-1 and SDF-1 expressions. (B) Comparisons of TIMP-1, CXCR4, ICAM-1 and ICAM-2 expression. (C) Comparisons of EGF and EGFR expression. (D) Comparisons of TGF ( $a, \beta)$ and TGF- $\beta$ (R1, R2) expression. (E) Comparisons of FGF- $\beta$ and FGF (R1, R2, R3, R4) expression. (F) Comparisons of IGF $(1,2)$ and IGF (R1, R2) expression. (G) 
Comparisons of VEGFA and VEGF (R1, R2, R3) expression. (H) Comparisons of myocardiocyte's markers (CX43, GATA-4, MYH6, NKX2.5) expression. * $p<0.05$.

A.

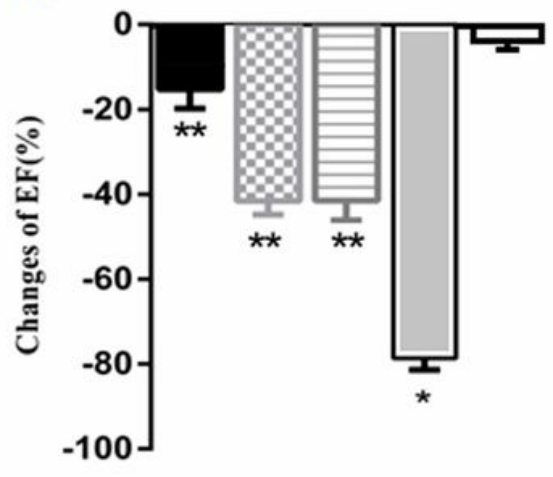

C.

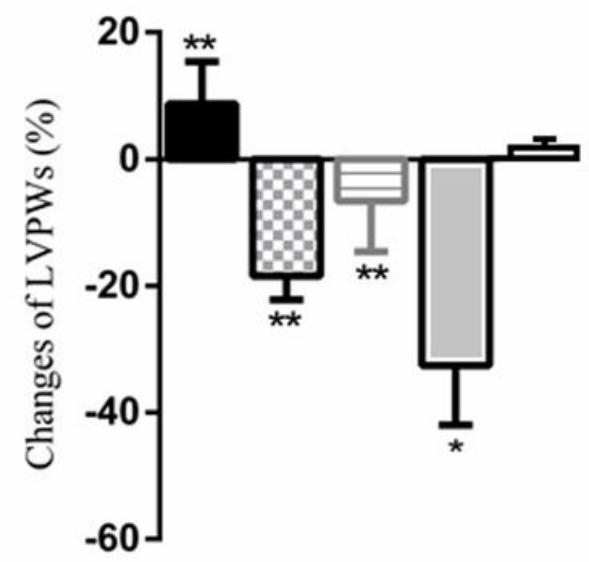

B.

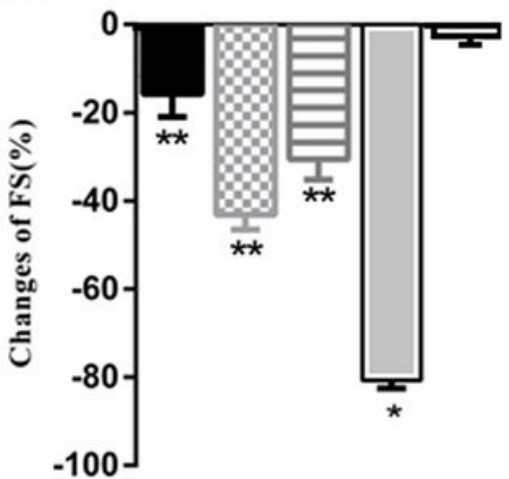

D.

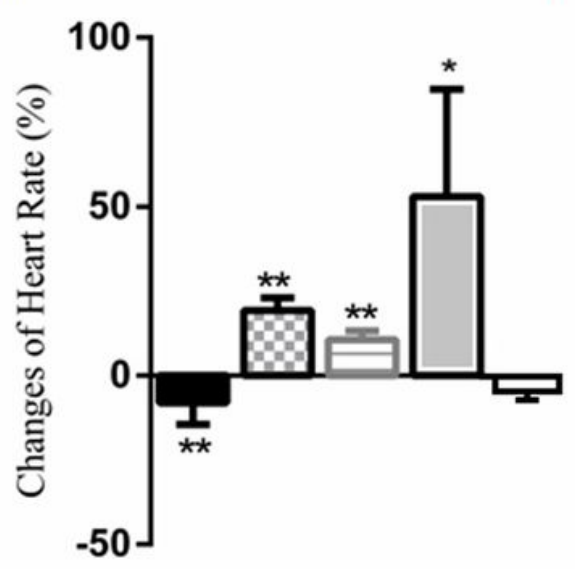

E.

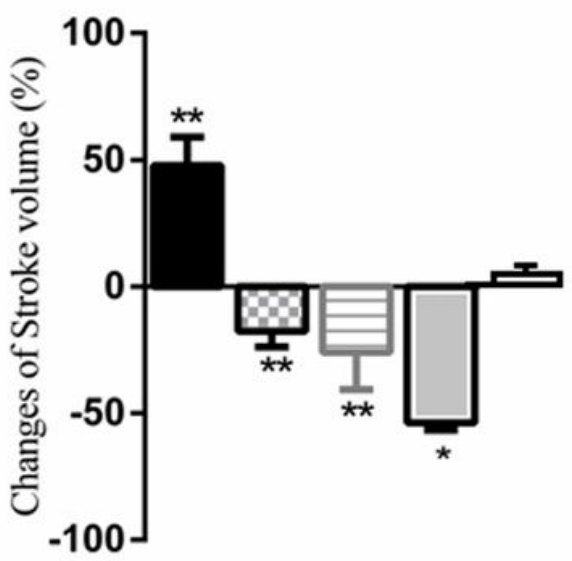

Figure 3

Echocardiographic assessment of cardiac function after myocardial infarction with stem cell transfusion. The change of cardiac functional parameters of mice were compared between before ( $0 \mathrm{~d})$ and after (30d) myocardial infarction with stem cell transfusion. The change of EF (A), FS (B), LVPWs (C), SV (D) and HR (E) were compared between each group. ${ }^{*} p<0.05$, compared with sham group; ${ }^{* \star} p<0.05$, compared with PBS group. Abbreviations: EF, ejection fraction; FS, fractional shortening; LVPW, Left Ventricular Posterior Wall; SV, Stroke Volume; HR, Heart Rate. 


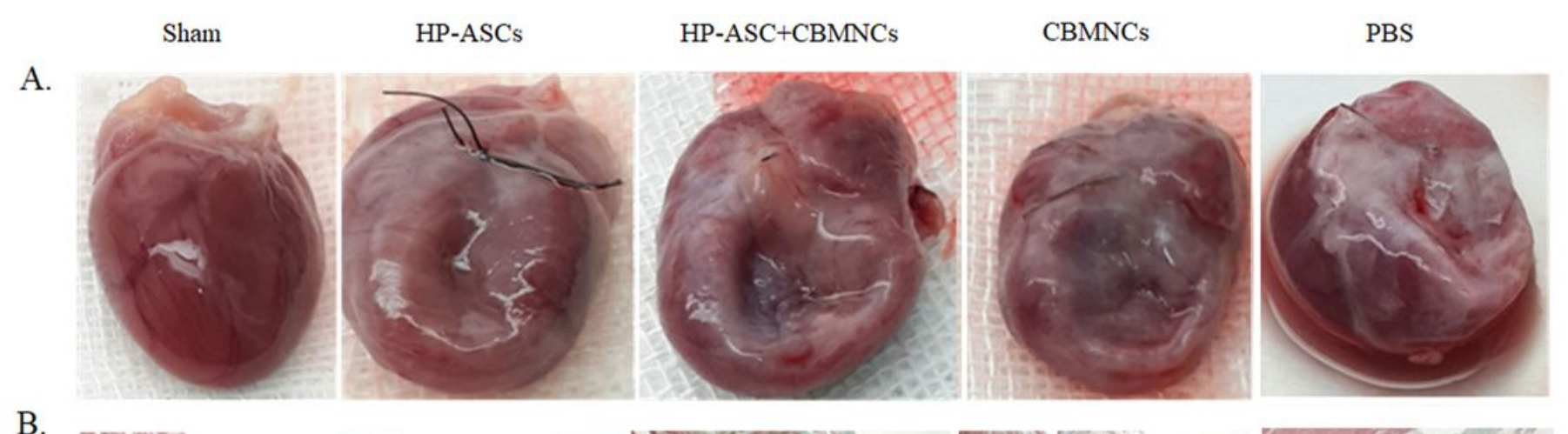

B.

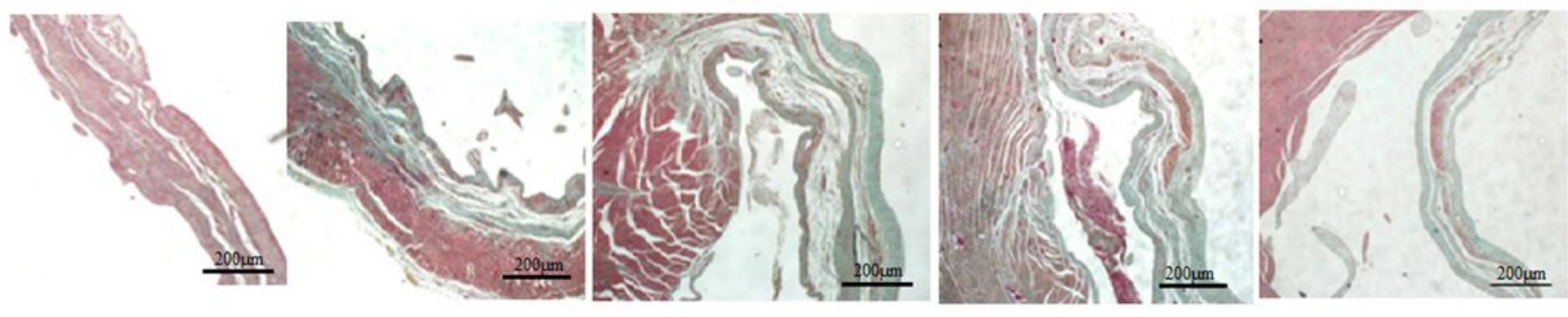

C.

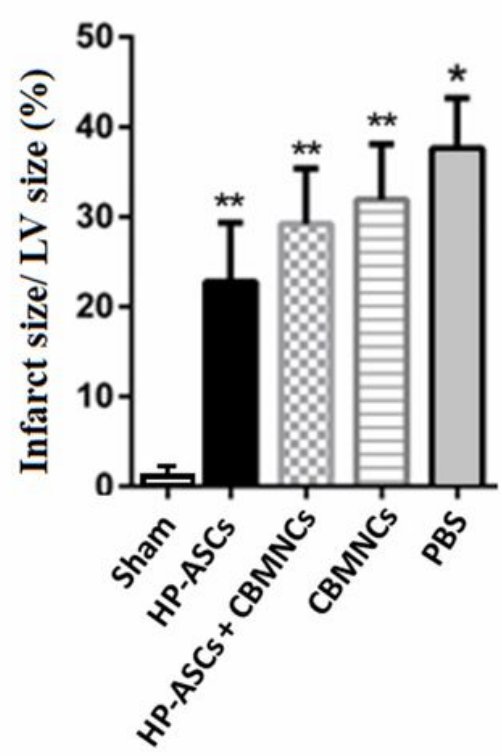

D.

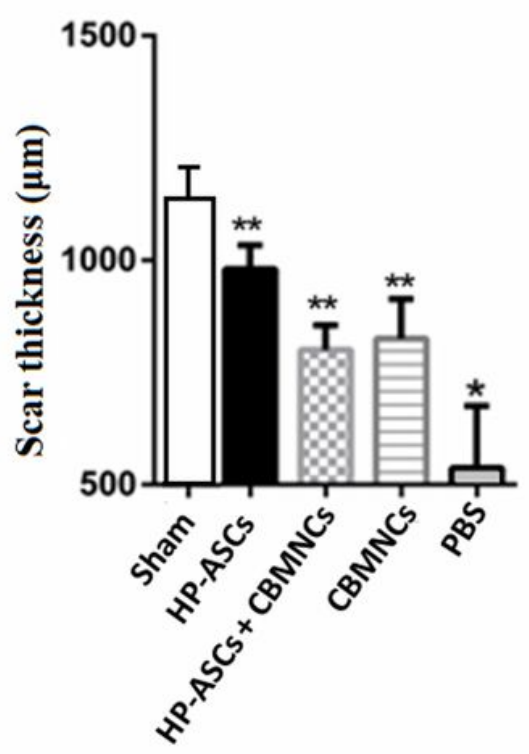

Figure 4

Analysis of cardiac fibrosis 30 days after myocardial infarction. (A) General morphometric fibrosis of Sham group, HP-ASCs group, HP-ASCs + CBMNCs group, CBMNCs group and PBS group. (B) Mouse cardiac cross-sections assessed by Masson's trichrome staining in each group. (C) Comparisons of the percentage of the mouse LV fibrotic size / LV area between groups. (D) Comparisons of the average thickness of scars between groups. ${ }^{*} p<0.05$, compared with sham group; ${ }^{* \star} p<0.05$, compared with PBS group. 
A.

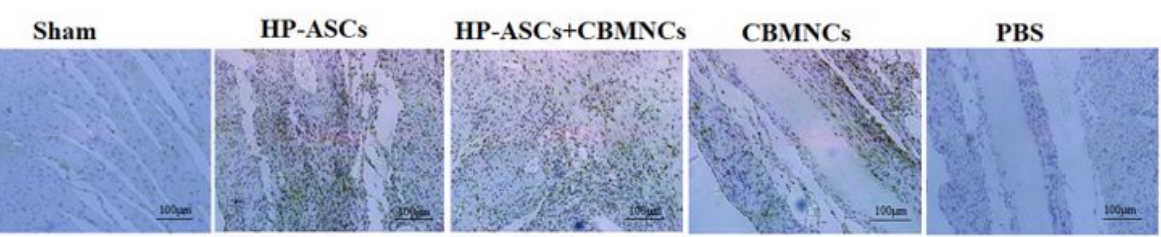

B.

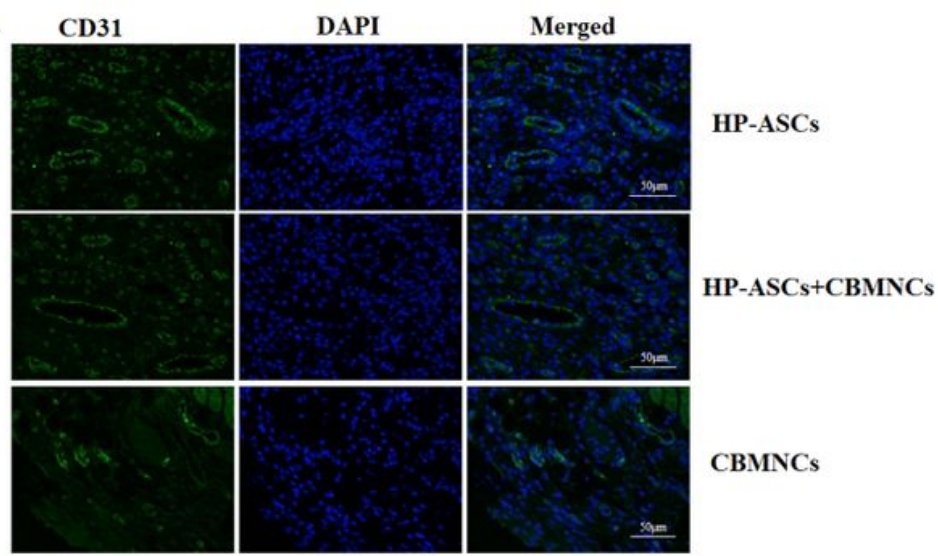

C.

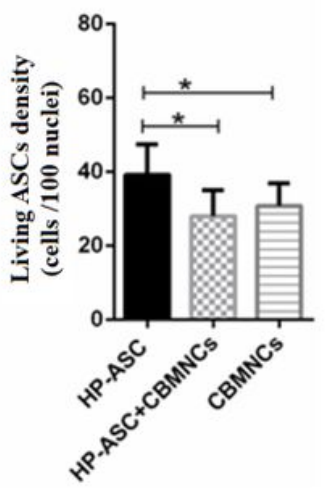

D.

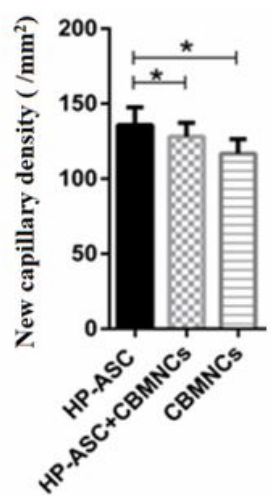

\section{Figure 5}

Comparison of live ASCs and new formed vessels 30 days after myocardial infarction with stem cell transfusions. (A) Live ASCs (from human male) were stained with anti-human SRY antibody, and calculated under microscopy (x100). (B) New formed vessels (stained with anti-human CD31 antibody, green) were calculated under microscopy (x200). Nuclei were stained with DAPI(blue). (C) Living ASCs densities (cells/mm2) were compared between HP-ASCs group, HP-ASCs + CBMNCs group and CBMNCs group. (D) The number of new formed vessels were compared between HP-ASCs group, HP-ASCs + CBMNCs group and CBMNCs group. ${ }^{*} \mathrm{p}<0.05$.

\section{Supplementary Files}

This is a list of supplementary files associated with this preprint. Click to download.

- graphicabstract.tif

- Supplementtable1.docx 